\title{
Adolescents' leisure activities, parental monitoring and cigarette smoking - a cross-sectional study
}

\author{
Hui Guo', Anthony I Reeder ${ }^{1 *}$, Rob McGee ${ }^{1}$ and Helen Darling ${ }^{1,2}$
}

\begin{abstract}
Background: Adolescent participation in leisure activities is developmentally beneficial, but certain activities may increase health compromising behaviours, such as tobacco smoking. A limited range of leisure activities has been studied, with little research on out-of-school settings where parental supervision is a potential protective factor. Tobacco smoking is an important, potentially modifiable health determinant, so understanding associations between adolescent leisure activities, parental monitoring, demographic factors and daily smoking may inform preventive strategies. These associations are reported for a New Zealand adolescent sample.

Methods: Randomly selected schools $(n=145)$ participated in the 2006 Youth In-depth Survey, a national, biennial study of Year 10 students (predominantly 14-15 years). School classes were randomly selected and students completed a self-report questionnaire in class time. Adjustment for clustering at the school level was included in all analyses. Since parental monitoring and demographic variables potentially confound relations between adolescent leisure activities and smoking, variables were screened before multivariable modelling. Given prior indications of demographic differences, gender and ethnic specific regression models were built.

Results and Discussion: Overall, 8.5\% of the 3,161 students were daily smokers, including more females (10.5\%) than males (6.5\%). In gender and ethnic specific multivariate analysis of associations with daily smoking (adjusted for age, school socioeconomic decile rating, leisure activities and ethnicity or gender, respectively), parental monitoring exhibited a consistently protective, dose response effect, although less strongly among Māori. Attending a place of worship and going to the movies were protective for non-Māori, as was watching sports, whereas playing team sport was protective for all, except males. Attending a skate park was a risk factor for females and Māori which demonstrated a strong dose response effect.

Conclusions: There were significant differences in the risk of daily smoking across leisure activities by gender and ethnicity. This reinforces the need to be alert for, and respond to, gender and ethnic differences in the pattern of risk and protective factors. However, given the consistently protective, dose response effect of parental monitoring, our findings confirm that assisting oversight of adolescent leisure activities may be a key component in public health policy and prevention programmes.
\end{abstract}

\footnotetext{
* Correspondence: tony.reeder@otago.ac.nz

${ }^{1}$ Cancer Society of New Zealand Social and Behavioral Research Unit (SBRU), Department of Preventive and Social Medicine, Dunedin School of Medicine, University of Otago, Dunedin, New Zealand

Full list of author information is available at the end of the article
} 


\section{Background}

It has long been known that involvement in leisure activities can assist adolescents in exerting personal control over their environments and developing a positive sense of identity through their actions [1]. Physical activities programmes can 'help children develop social skills, improve mental health, and reduce risk-taking behaviours.' [2] Participation in organised activities, such as team sport, is often associated with reduced involvement in antisocial behaviours and substance use, [3-5] including tobacco smoking [6]. In particular, team sports involvement has been associated with lower levels of cigarette smoking, [7] and consistent, high and multiple participation in team sports over a number of years may provide particularly effective protection when compared with more intermittent patterns of participation [8].

A possible explanation for these observations is that organised activities may be protective by facilitating pro-social group membership [3,9]. The protective effect may be attributable to displacement, whereby the time available to spend in unstructured activities with antisocial peers is reduced [6]. A New Zealand study found that moderate or high levels of involvement in physical activity, but not team sports at age 15 years, were associated with antisocial behaviours for both sexes at age 18 years [10]. Using structural equation modelling, a recent longitudinal study found significant associations between adolescents' activities at baseline and tobacco smoking 24 months later [11]. Interestingly, the pathways differed by activity type and sex. For girls, an indirect path from baseline participation in school clubs and activities lay through reduced association with 'problem peers' at 15 months follow up, whereas for boys baseline participation in team sports was linked to tobacco smoking through on-going team sports participation at 15 months. Overall, it is possible that less structured leisure activities may leave participants at increased risk of experimentation with health compromising behaviours such as tobacco smoking, whereas other activities and settings, such as team sports and club membership, may provide a more protective social and physical environment [6].

Faith-based activities have also been identified as potentially protective against substance use and antisocial behaviours [3]. When adjusted for baseline smoking, religious activity was associated with tobacco smoking at 24 months for both sexes [11]. For girls, baseline religious activity indirectly reduced tobacco smoking at 24 months by reducing exposure to problem peers at 15 months, whereas for boys the path lay through religious activity at 15 months, which was directly related to lower levels of tobacco smoking at 24 months. These differences suggest the potential informative value for policy development of gender specific analyses, and the same may be true for analysis by ethnicity [12].

To date, the range of leisure activities studied in relation to tobacco use has been limited, with relatively little research on out-of-school settings, but there is evidence of a protective effect for some other problem behaviours, such as marijuana use [13]. In the study reported here, we examined daily cigarette smoking in a variety of social contexts including attending a place of worship, which suggests a shared set of values or sense of community; involvement in team sports and voluntary work, which may promote social and physical well-being; and engagement in musical activities, movies and skate boarding, which represent contexts perhaps most likely to be influenced by informal group processes.

Parents may have different degrees of awareness of the activities in which their adolescents participate, but parental monitoring is a potentially important protective factor against adolescent smoking [14]. For example, secondary school students who were home alone on two or more days per week were more likely to smoke than those having parental supervision five or more times a week [15]. Of particular relevance in the present context, parental monitoring may also influence an adolescent's choice of activities and potentially confound the observed relationships between leisure activities and adolescent smoking. Accordingly, in this study we used multivariable modelling to examine whether any observed effects associated with leisure activities may simply reflect less parental monitoring or whether parental monitoring and various leisure activities are each independently associated with tobacco smoking.

Given that tobacco use is an important and potentially modifiable determinant of health, understanding more about the associations of leisure activities, socio-demographic factors and parental monitoring with adolescent smoking may help inform and guide the development and targeting of preventive policies and protective strategies. Most adult smokers started smoking in adolescence, so identifying which factors may increase risk or exert protective effects against smoking during that period of life may be particularly important for the design and targeting of preventive interventions [11].

\section{Method \\ Sample selection}

The Year 10 Youth In-depth Survey (YIS) is a biennial survey carried out by the Health Sponsorship Council of $\mathrm{NZ}$ with methods and key measures from the international Global Youth Tobacco Survey (GYTS) [16]. Our study uses data from the 2006 survey of Year 10 (predominantly 14-15 year-old) students from randomlyselected secondary schools. The survey used a self-report 
questionnaire administered during class time. Of the 186 randomly selected schools, 145 or $78 \%$ agreed to participate [17]. Ethical approval for analyzing the data was obtained through the Department of Preventive and Social Medicine, following University of Otago procedures.

\section{Measures}

The outcome variable, daily smoking, was assessed by the question "how often do you smoke now?" with those students who responded "at least once a day" categorized as daily smokers. Students were also asked the frequency of engaging in a variety of activities during the month preceding the survey, including: attending a place of worship, attending a music event or concert, visiting a music shop, watching a movie in a theatre, visiting a skate-park, playing sports for a team during the weekend or after school, going somewhere to watch a sports game or event, and doing community voluntary work. The response categories for the past month were: $0,1-3$, or $4+$ times (i.e., at least weekly). Parental monitoring outside of school hours was assessed using a 4item scale adapted from the NZ Youth 2000 survey [18] and the Centers for Disease Control (CDC) "Got a minute" parenting campaign measurement tool [19]. Participants were asked whether they agreed or disagreed with the following statements, "My parents or caregivers": "generally know what I spend my pocket money on"; "have rules about when I can go out with my friends"; "often have no idea where I am, when I am away from my home"; and "If I break any important rules that my parents or caregivers have set I always get into trouble." The scale demonstrated acceptable internal consistency (Cronbach's alpha $=0.69)$. It was not considered appropriate to ask students about household income in order to estimate family socioeconomic status (SES). Instead, school socio-economic decile, which provides a measure of the relative poverty of the parents or care-givers of students at a school, was used as a proxy measure of SES. Deciles 1 and 10, respectively, include the $10 \%$ of schools drawing students from the lowest and highest socioeconomic communities. For the purpose of descriptive comparison the scale was collapsed into three categories with deciles 1 to 4 being 'low', 5 to 7 'mid' and 8 to 10 'high' SES, [16] but treated as a continuous variable in the regression analyses.

\section{Statistical analyses}

Stata version 10.1 was used for all the analyses [20]. As data were collected from individuals within selected schools, adjustment for clustering at the school level was included in all analyses. Weights were calculated from the total number of students in each school year for each randomly selected school. Simple logistic regression was used to examine the associations between potential predictor variables and the binary outcome variable adolescent daily smoking. As the bivariate modeling was exploratory, a $p$-value of $\leq 0.20$ was used as the cut off value for the selection of explanatory variables for multivariate analysis [21]. Four multiple logistic regression models (for males and females, Māori and non-Māori) were used to examine the associations of parental monitoring scores and participation in the selected activities with the binary outcome variable, adolescent smoking. These four models were adjusted for student age, school socioeconomic decile and either ethnicity or sex, as appropriate. The results are presented as unadjusted or adjusted odds ratios (OR) with 95\% confidence intervals (CI's). The relation between each pair of the predictor variables was checked using Spearman's correlations so that if any variables were strongly correlated $(|\mathrm{r}|$ $<0.70$ ), only a single variable would be included in each model to minimize problems associated with collinearity. However, the highest correlation was between watching a sports event and playing sport $(r=0.44)$.

\section{Results}

Students $(n=39)$ who did not provide full data about their age, sex, ethnicity and tobacco smoking status were excluded from the study, leaving 3,161 participants: $51 \%$ females and $49 \%$ males. Of these, $8.5 \%$ and more females $(10.5 \%)$ than males $(6.5 \%)$ were daily smokers. More Māori students (20.5\%) were daily smokers than non-Māori (7.2\%). The socio-demographic characteristics of the sample are presented in Table 1.

The distribution of all students and daily smokers engaging in the eight leisure activities are presented in Table 2 along with the distribution of parental monitoring scores.

The results of the logistic regression analyses by sex and by ethnicity are presented in Tables 3 and 4 , respectively.

Parental monitoring exhibited a protective, dose response effect for both sexes, whereby increasing monitoring scores were associated with decreasing odds of daily smoking. Playing team sports demonstrated a protective effect, but only among females. In contrast, going to a skate park was positively associated with daily smoking, most strongly among females in the multivariable model. Having done voluntary work was a risk factor among males, but this was relatively weak in a multivariable context whereas going to the movies and a music event/concert lost significance as a risk factor for both sexes in the multivariable modeling.

Parental monitoring score was protective against daily smoking for non-Māori, exhibiting a strong dose response effect. However, for Māori, it became only weakly protective in a multivariable context. For non- 
Table 1 Socio-demographic characteristics of the YIS 2006 sample

\begin{tabular}{|c|c|c|c|c|}
\hline & \multicolumn{2}{|c|}{$\begin{array}{r}\text { Current daily smokers } \\
\qquad(\mathrm{n}=269)\end{array}$} & \multicolumn{2}{|c|}{$\begin{array}{r}\text { YIS } 2006 \text { sample } \\
(n=3161)\end{array}$} \\
\hline & $\mathrm{n}$ & $\% *$ & $\mathrm{n}$ & $\% *$ \\
\hline \multicolumn{5}{|l|}{ Age } \\
\hline 13 yrs & 2 & 0.7 & 24 & 0.8 \\
\hline 14 yrs & 166 & 61.7 & 2035 & 64.3 \\
\hline 15 yrs & 96 & 35.7 & 1069 & 33.8 \\
\hline 16 yrs & 4 & 1.5 & 24 & 0.8 \\
\hline 17 yrs & 1 & 0.4 & 5 & 0.2 \\
\hline$\geq 18 \mathrm{yrs}$ & 0 & 0 & 4 & 0.1 \\
\hline \multicolumn{5}{|l|}{ Sex } \\
\hline Female & 168 & 62.5 & 1606 & 50.8 \\
\hline Male & 101 & 37.5 & 1555 & 49.2 \\
\hline \multicolumn{5}{|l|}{ Ethnicity } \\
\hline NZ European & 90 & 33.5 & 1724 & 54.6 \\
\hline Māori & 134 & 49.8 & 654 & 20.7 \\
\hline Pacific Island & 25 & 9.3 & 271 & 8.6 \\
\hline Asian & 3 & 1.1 & 294 & 9.3 \\
\hline Other & 17 & 6.3 & 218 & 6.8 \\
\hline \multicolumn{5}{|l|}{ School decile } \\
\hline low & 114 & 34.5 & 849 & 26.9 \\
\hline mid & 108 & 41.4 & 1198 & 37.9 \\
\hline high & 47 & 24.1 & 1114 & 35.2 \\
\hline
\end{tabular}

*Weighted \% (probability weights assigned at individual student level)

Māori, going to a place of worship, watching sports, playing team sports and going to the movies were all protective and there were no statistically significant risk factors in the multivariable model. However, among Māori, playing team sports was protective and parental monitoring score was only weakly protective, whereas going to a skate park was a risk factor with strong dose response characteristics.

\section{Discussion}

Adolescence is a pivotal period for psychosocial and physical development during which life experiences and social contexts can shape the positive-to-negative balance of outcomes [22]. Although quite a lot is known about family and peer effects on adolescent tobacco smoking, fewer studies have examined the possible influence of leisure activities and none, so far as we could ascertain, have done this in the context of multivariate analyses that also included parental monitoring as a potential predictor.

Our finding that parental monitoring was universally strongly protective against adolescent daily tobacco smoking is consistent with other recent evidence [12,23]. However, the effects observed those studies did not take into account the associations between tobacco smoking and participation in leisure activities. We also found
Table 2 Descriptive results: parental monitoring scores and participation in activities

\begin{tabular}{|c|c|c|c|c|}
\hline & \multicolumn{2}{|c|}{$\begin{array}{r}\text { Current daily } \\
\text { smokers }\end{array}$} & \multicolumn{2}{|c|}{$\begin{array}{r}\text { YLS } 2006 \\
\text { sample }\end{array}$} \\
\hline & $\mathbf{N}$ & $\% *$ & n & $\% *$ \\
\hline \multicolumn{5}{|l|}{ Parental monitoring scores } \\
\hline 0 & 25 & 10.6 & 219 & 7.1 \\
\hline 1 & 61 & 23.7 & 375 & 12.1 \\
\hline 2 & 72 & 27.0 & 696 & 22.5 \\
\hline 3 & 72 & 31.1 & 931 & 30.2 \\
\hline 4 & 27 & 7.6 & 867 & 28.1 \\
\hline \multicolumn{5}{|l|}{ Gone to a place of worship } \\
\hline Not in past month & 97 & 77.4 & 1865 & 65.0 \\
\hline $1-3$ times & 110 & 8.7 & 453 & 15.6 \\
\hline 4 or more times & 40 & 14.0 & 565 & 19.4 \\
\hline \multicolumn{5}{|l|}{ Watched sports game or event } \\
\hline Not in past month & 68 & 35.5 & 1036 & 34.9 \\
\hline $1-3$ times & 97 & 38.0 & 1165 & 39.0 \\
\hline 4 or more times & 73 & 26.5 & 774 & 26.0 \\
\hline \multicolumn{5}{|l|}{ Played team sports } \\
\hline Not in past month & 130 & 57.1 & 1180 & 40.5 \\
\hline $1-3$ times & 33 & 14.1 & 489 & 16.5 \\
\hline 4 or more times & 75 & 28.8 & 1290 & 43.0 \\
\hline \multicolumn{5}{|l|}{ Done voluntary work } \\
\hline Not in past month & 196 & 88.0 & 2480 & 90.2 \\
\hline $1-3$ times & 7 & 3.7 & 163 & 5.9 \\
\hline 4 or more times & 18 & 8.3 & 108 & 3.9 \\
\hline \multicolumn{5}{|l|}{ Gone to the movies } \\
\hline Not in past month & 97 & 40.3 & 1249 & 41.7 \\
\hline $1-3$ times & 110 & 42.8 & 1508 & 50.2 \\
\hline 4 or more times & 40 & 16.9 & 232 & 8.1 \\
\hline \multicolumn{5}{|l|}{ Gone to a skate park } \\
\hline Not in past month & 118 & 54.0 & 2152 & 73.9 \\
\hline $1-3$ times & 64 & 25.6 & 524 & 18.3 \\
\hline 4 or more times & 54 & 20.4 & 221 & 7.8 \\
\hline \multicolumn{5}{|l|}{ Gone to a music event/concert } \\
\hline Not in past month & 147 & 60.1 & 2099 & 73.0 \\
\hline $1-3$ times & 81 & 35.1 & 724 & 24.6 \\
\hline 4 or more times & 11 & 4.8 & 68 & 2.4 \\
\hline \multicolumn{5}{|l|}{ Gone to a music shop } \\
\hline No visits & 98 & 39.4 & 1439 & 49.5 \\
\hline $1-3$ times & 97 & 41.5 & 1131 & 38.4 \\
\hline 4 or more times & 44 & 19.1 & 356 & 12.1 \\
\hline
\end{tabular}

*Weighted \% (probability weights assigned at individual student level)

evidence of a protective effect against smoking among those who engaged in extracurricular team sports, consistent with earlier US studies of adolescents who participated in school-based team sports [24-26]. However, we found that this only held true for females, which is the reverse of the relationship found in a recent longitudinal study [11]. It is possible that this may relate to cultural differences between the US and NZ regarding sports 
Table 3 Unadjusted and adjusted OR for male and female daily smoking and adolescent activities, YIS 2006

\begin{tabular}{|c|c|c|c|c|c|c|c|c|}
\hline & \multicolumn{4}{|c|}{ Males } & \multicolumn{4}{|c|}{ Females } \\
\hline & $\begin{array}{l}\text { Unadjusted } \\
\text { OR }(95 \% \mathrm{Cl})\end{array}$ & $\begin{array}{c}\text { Overall } \\
\text { p-value }\end{array}$ & $\begin{array}{c}\text { Adjusted }^{1} \\
\text { OR }(95 \% \mathrm{Cl})\end{array}$ & $\begin{array}{c}\text { Overall } \\
\text { p-value }\end{array}$ & $\begin{array}{l}\text { Unadjusted } \\
\text { OR }(95 \% \mathrm{Cl})\end{array}$ & $\begin{array}{c}\text { Overall } \\
\text { p-value }\end{array}$ & $\begin{array}{r}\text { Adjusted }^{1} \\
\text { OR }(95 \% \mathrm{Cl})\end{array}$ & $\begin{array}{l}\text { Overall } \\
\text { p-value }\end{array}$ \\
\hline Parental monitoring score & & $<0.001$ & & 0.003 & & $<0.001$ & & $<0.001$ \\
\hline 0 & 1.0 & & 1.0 & & 1.0 & & 1.0 & \\
\hline 1 & $0.70(0.60,0.82)$ & & $0.77(0.65,0.92)$ & & $0.65(0.57,0.75)$ & & $0.73(0.62,0.86)$ & \\
\hline 2 & $0.50(0.37,0.67)$ & & $0.60(0.42,0.84)$ & & $0.43(0.33,0.56)$ & & $0.53(0.38,0.73)$ & \\
\hline 3 & $0.35(0.22,0.55)$ & & $0.46(0.28,0.77)$ & & $0.28(0.19,0.42)$ & & $0.38(0.24,0.63)$ & \\
\hline 4 & $0.25(0.13,0.46)$ & & $0.36(0.18,0.71)$ & & $0.18(0.11,0.31)$ & & $0.28(0.15,0.53)$ & \\
\hline Gone to a place of worship & & 0.240 & & N/A & & 0.037 & & 0.212 \\
\hline No visits & 1.0 & & & & 1.0 & & 1.0 & \\
\hline $1-3$ visits & $0.44(0.17,1.17)$ & & & & $0.65(0.38,1.10)$ & & $0.77(0.43,1.39)$ & \\
\hline 4 or more visits & $1.02(0.51,2.03)$ & & & & $0.50(0.27,0.92)$ & & $0.55(0.27,1.13)$ & \\
\hline Watched sports game or event & & 0.534 & & N/A & & 0.081 & & 0.431 \\
\hline No visits & 1.0 & & & & 1.0 & & 1.0 & \\
\hline $1-3$ visits & $0.78(0.44,1.38)$ & & & & $1.86(1.08,3.21)$ & & $1.48(0.82,2.68)$ & \\
\hline 4 or more visits & $1.12(0.57,2.19)$ & & & & $1.50(0.86,2.60)$ & & $1.30(0.69,2.44)$ & \\
\hline Played team sports & & 0.068 & & 0.096 & & $<0.001$ & & 0.002 \\
\hline No visits & 1.0 & & 1.0 & & 1.0 & & 1.0 & \\
\hline $1-3$ visits & $0.54(0.24,1.20)$ & & $0.63(0.26,1.55)$ & & $0.64(0.38,1.16)$ & & $0.51(0.27,0.97)$ & \\
\hline 4 or more visits & $0.52(0.28,0.96)$ & & $0.46(0.23,0.93)$ & & $0.42(0.27,0.63)$ & & $0.40(0.24,0.67)$ & \\
\hline Done voluntary work & & 0.003 & & 0.020 & & 0.622 & & N/A \\
\hline No visits & 1.0 & & 1.0 & & 1.0 & & & \\
\hline $1-3$ visits & $0.28(0.04,1.86)$ & & $0.22(0.03,1.92)$ & & $0.68(0.27,1.69)$ & & & \\
\hline 4 or more visits & $4.02(1.75,9.24)$ & & $3.51(1.26,9.32)$ & & $1.23(0.53,2.82)$ & & & \\
\hline Gone to the movies & & $<0.001$ & & 0.260 & & 0.004 & & 0.184 \\
\hline No visits & 1.0 & & 1.0 & & 1.0 & & 1.0 & \\
\hline $1-3$ visits & $0.99(0.58,1.68)$ & & $0.94(0.54,1.64)$ & & $0.84(0.54,1.31)$ & & $0.97(0.62,1.54)$ & \\
\hline 4 or more visits & $3.72(1.87,7.40)$ & & $1.83(0.80,4.17)$ & & $2.39(1.26,4.54)$ & & $2.24(0.91,5.50)$ & \\
\hline Gone to a skate park & & $<0.001$ & & 0.027 & & $<0.001$ & & $<0.001$ \\
\hline No visits & 1.0 & & 1.0 & & 1.0 & & 1.0 & \\
\hline $1-3$ visits & $1.52(0.73,3.17)$ & & $1.14(0.54,2.39)$ & & $2.96(1.98,4.43)$ & & $1.95(1.21,3.15)$ & \\
\hline 4 or more visits & $4.24(1.95,7.90)$ & & $2.61(1.28,5.32)$ & & $9.45(4.96,18.01)$ & & $5.13(2.49,10.57)$ & \\
\hline Gone to a music event/concert & & 0.001 & & 0.092 & & 0.010 & & 0.135 \\
\hline No visits & 1.0 & & 1.0 & & 1.0 & & 1.0 & \\
\hline $1-3$ visits & $2.46(1.54,3.91)$ & & $1.78(1.10,2.98)$ & & $1.17(0.77,1.78)$ & & $0.93(0.58,1.49)$ & \\
\hline 4 or more visits & $2.11(0.52,8.58)$ & & $1.86(0.13,6.56)$ & & $3.41(1.56,7.45)$ & & $2.56(0.97,6.81)$ & \\
\hline Gone to a music shop & & 0.089 & & 0.520 & & 0.062 & & 0.949 \\
\hline No visits & 1.0 & & 1.0 & & 1.0 & & 1.0 & \\
\hline $1-3$ visits & $1.21(0.65,2.24)$ & & $1.21(0.63,2.33)$ & & $1.09(0.73,1.65)$ & & $1.01(0.63,1.64)$ & \\
\hline 4 or more visits & $2.40(1.18,4.90)$ & & $1.64(0.70,3.81)$ & & $1.81(1.09,3.02)$ & & $0.91(0.46,1.83)$ & \\
\hline
\end{tabular}

participation, and is worthy of further investigation. There is evidence that team sports participation can be a risk factor for other adolescent health risk behaviours, such as alcohol use, [9] but legislative control of smoking in shared indoor environments in $\mathrm{NZ}$, including sports clubs, would tend to limit the risk of tobacco smoking.

We found some evidence of an increased risk of daily smoking among those who reported going to musical events, the movies and music shops, but in multivariate analysis only going to the movies was associated with daily smoking and as a protective factor among nonMāori. Going to a skate park was the strongest predictor, but in a multivariable context it was a statistically significant risk factor only for females and Māori, demonstrating a dose response effect in each case. Although clearly not universal in our sample, this finding is consistent with the UK research which suggests that street-oriented leisure activities are associated with a greater risk of tobacco smoking [27]. 
Table 4 Unadjusted and adjusted OR for Māori and non-Māori daily smoking by parental monitoring and activities

\begin{tabular}{|c|c|c|c|c|c|c|c|c|}
\hline & & & iori & & & Non- & Māori & \\
\hline & $\begin{array}{l}\text { Unadjusted } \\
\text { OR }(95 \% \mathrm{Cl})\end{array}$ & $\begin{array}{l}\text { Overall } \\
\text { p-value }\end{array}$ & $\begin{array}{c}\text { Adjusted }^{1} \\
\text { OR }(95 \% \mathrm{Cl})\end{array}$ & $\begin{array}{l}\text { Overall } \\
\text { p-value }\end{array}$ & $\begin{array}{l}\text { Unadjusted } \\
\text { OR }(95 \% \mathrm{Cl})\end{array}$ & $\begin{array}{l}\text { Overall } \\
\text { p-value }\end{array}$ & $\begin{array}{c}\text { Adjusted }^{1} \\
\text { OR }(95 \% \mathrm{Cl})\end{array}$ & $\begin{array}{l}\text { Overall } \\
\mathrm{p} \text {-value }\end{array}$ \\
\hline Parental monitoring scores & & 0.008 & & 0.030 & & & & $<0.001$ \\
\hline 0 & 1.0 & & 1.0 & & 1.0 & & 1.0 & \\
\hline 1 & $0.81(0.70,0.95)$ & & $0.82(0.65,0.92)$ & & $0.53(0.33,0.85)$ & & $0.51(0.44,0.60)$ & \\
\hline 2 & $0.66(0.49,0.90)$ & & $0.67(0.47,0.96)$ & & $0.28(0.11,0.73)$ & & $0.26(0.20,0.35)$ & \\
\hline 3 & $0.54(0.34,0.85)$ & & $0.55(0.33,0.94)$ & & $0.15(0.04,0.62)$ & & $0.14(0.09,0.21)$ & \\
\hline 4 & $0.44(0.24,0.81)$ & & $0.46(0.22,0.93)$ & & $0.08(0.01,0.53)$ & & $0.07(0.04,0.13)$ & \\
\hline Gone to a place of worship & & 0.341 & & N/A & & $<0.001$ & & $<0.001$ \\
\hline No visits & 1.0 & & & & 1.0 & & 1.0 & \\
\hline $1-3$ visits & $0.73(0.37,1.44)$ & & & & $0.11(0.05,0.22)$ & & $0.22(0.08,0.61)$ & \\
\hline 4 or more visits & $0.65(0.32,1.31)$ & & & & $0.17(0.09,0.32)$ & & $0.30(0.15,0.60)$ & \\
\hline Watched sports game or event & & 0.211 & & N/A & & $<0.001$ & & $<0.001$ \\
\hline Not in past month & 1.0 & & & & 1.0 & & 1.0 & \\
\hline $1-3$ times & $1.57(0.82,3.02)$ & & & & $0.11(0.08,0.17)$ & & $0.43(0.28,0.64)$ & \\
\hline 4 or more times & $1.03(0.54,1.98)$ & & & & $0.15(0.10,0.21)$ & & $0.77(0.43,1.38)$ & \\
\hline Played team sports & & $<0.001$ & & $<0.001$ & & $<0.001$ & & $<0.001$ \\
\hline Not in past month & 1.0 & & 1.0 & & 1.0 & & 1.0 & \\
\hline 1-3 times & $0.48(0.26,0.91)$ & & $0.41(0.20,0.87)$ & & $0.10(0.05,0.19)$ & & $0.33(0.15,0.73)$ & \\
\hline 4 or more times & $0.44(0.27,0.70)$ & & $0.38(0.23,0.64)$ & & $0.08(0.06,0.12)$ & & $0.29(0.16,0.50)$ & \\
\hline Done voluntary work & & 0.108 & & 0.093 & & $<0.001$ & & 0.449 \\
\hline Not in past month & 1.0 & & 1.0 & & 1.0 & & 1.0 & \\
\hline 1-3 times & $0.38(0.09,1.63)$ & & $0.30(0.06,1.55)$ & & $0.17(0.06,0.46)$ & & $0.53(0.13,2.17)$ & \\
\hline 4 or more times & $2.16(0.83,5.61)$ & & $2.26(0.82,6.25)$ & & $0.47(0.22,1.01)$ & & $1.82(0.55,6.02)$ & \\
\hline Gone to the movies & & 0.131 & & 0.310 & & $<0.001$ & & $<0.001$ \\
\hline Not in past month & 1.0 & & 1.0 & & 1.0 & & 1.0 & \\
\hline $1-3$ times & $0.95(0.57,1.60)$ & & $1.15(0.67,1.97)$ & & $0.12(0.09,0.16)$ & & $0.46(0.31,0.66)$ & \\
\hline 4 or more times & $1.89(0.90,3.97)$ & & $1.90(0.83,4.37)^{*}$ & & $0.42(0.22,0.80)$ & & $0.89(0.30,2.62)$ & \\
\hline Gone to a skate park & & $<0.001$ & & $<0.001$ & & $<0.001$ & & 0.347 \\
\hline Not in past month & 1.0 & & 1.0 & & 1.0 & & 1.0 & \\
\hline $1-3$ times & $1.73(1.01,2.96)$ & & $1.62(0.72,3.23)$ & & $0.42(0.27,0.64)$ & & $1.33(0.73,2.43)$ & \\
\hline 4 or more times & $4.21(2.25,7.99)$ & & $4.74(2.32,9.69)$ & & $0.82(0.47,1.42)$ & & $1.81(0.70,4.70)$ & \\
\hline Gone to a music event/concert & & 0.393 & & N/A & & $<0.001$ & & 0.251 \\
\hline Not in past month & 1.0 & & & & 1.0 & & $1.0 \S$ & \\
\hline $1-3$ times & $1.06(0.61,1.84)$ & & & & $0.38(0.27,0.54)$ & & $1.50(0.92,2.46)$ & \\
\hline 4 or more times & $2.44(0.67,8.88)$ & & & & $0.72(0.33,1.57)$ & & $1.71(0.35,8.42)$ & \\
\hline Gone to a music shop & & 0.150 & & 0.053 & & $<0.001$ & & 0.142 \\
\hline No visits & 1.0 & & 1.0 & & 1.0 & & 1.0 & \\
\hline $1-3$ times & $1.20(0.72,2.00)$ & & $1.03(0.61,1.77)$ & & $0.17(0.12,0.24)$ & & $0.58(0.33,0.99)$ & \\
\hline 4 or more times & $1.77(1.00,3.16)$ & & $0.99(0.46,2.15)$ & & $0.32(0.20,0.51)$ & & $0.79(0.40,1.59)$ & \\
\hline
\end{tabular}

Although our data come from a national survey of Year 10 students with a reasonable participation rate (65.3\%), [17] the most obvious limitation is the use of a cross-sectional design to test for associations of potential risk and protective factors with daily smoking [11]. In spite of strong associations between some of the variables, and evidence of dose-response relationships, there is insufficient evidence to assert causal relations. Further studies should include prospective assessment in order to better understand the temporal relationship between these factors and adolescent smoking.

\section{Conclusions}

Study findings reinforce Kaufman and Fieden's statement that 'Young people should be studied within the broad social and environmental contexts in which they live' (p. S11) [28]. Better understanding of different aspects of youth leisure activities, and of parental 
monitoring, should help inform and strengthen the study of youth health behaviors and tobacco smoking prevention efforts. Our study findings reinforce the need to be alert for, and respond to gender [11] and ethnic [12] differences in the patterns of risk and protective factors. However, given our finding that parental monitoring score was a protective factor across gender and ethnicity, and demonstrated a consistent dose response effect, interventions that involve working with parents, such as the CDC's 'Got a minute' program, [19] are likely to be an important component for preventing adolescent tobacco smoking. That a less strong effect was observed for Māori adolescents may be related to high smoking rates among adult Māori, the reduction of which is currently a critical target for improving Māori Health, overall.

Greene and Bannerjee (2009) concluded that unsupervised time with adolescent peers was associated indirectly with smoking behavior through the mediation of association with delinquent peers [29]. This finding led those authors to suggest that "interventions designed to motivate adolescents without adult supervision to associate more with friends who engage in pro-social activities may eventually reduce adolescent smoking." However, this presents a challenge, especially given evidence that physical activity may be waning in many countries, particularly in clearly defined contexts such as school physical education, and organised sports [30]. This may also be true for NZ, but it is not clear because insufficient monitoring has been done. Given our finding of a protective effect for playing team sports, at least among females, such monitoring should be undertaken to help inform and guide policy and program development. In addition to the collection of more comprehensive data on a range of activities in successive crosssectional waves, an important contribution would be made by the initiation of longitudinal studies to disentangle causality, [29] since the years of adolescence present policy opportunities with the potential to influence long term health outcomes. Any policy initiatives to increase participation in leisure activities should aim to promote those activities which optimize health gains while minimizing health risks, and include the monitoring of venues, such as skate parks. As noted earlier, there is also a need to pay attention to potential group preferences, taking into account gender and ethnic differences.

Tobacco smoking is a key behavioral outcome for health in the short term but, even more importantly, because those adolescents who smoke, in particular regular smokers, are likely to continue to smoke into adulthood. As stated elsewhere, 'once dependence is established, the majority of smokers will then continue to smoke for nearly 40 years. Experimentation with cigarettes in adolescence clearly has major long-term implications for individual and public health.'(p. 122) [31] Given the range of serious negative health outcomes linked with smoking, further study of risk and protective factors for tobacco smoking in adolescence has great potential public health and policy significance.

\section{Acknowledgements and funding}

We thank the students for their participation. JG, AIR and the Cancer Society Social \& Behavioural Research Unit (SBRU) received funding from the Cancer Society of New Zealand Inc. and the University of Otago. RM receives support from the University of Otago. HD received support from the Cancer Society of New Zealand Inc., the University of Otago and the HSC while employed in the SBRU. The HSC was responsible for survey design and content, commissioning and overseeing data collection for the Youth InDepth survey. The HSC, a Crown Agency funded through the NZ Ministry of Health, and the Cancer Society of NZ Inc. supported the decision to publish.

\section{Author details}

'Cancer Society of New Zealand Social and Behavioral Research Unit (SBRU), Department of Preventive and Social Medicine, Dunedin School of Medicine, University of Otago, Dunedin, New Zealand. ${ }^{2}$ Oritain Global Ltd., 8 Pacific St., Dunedin, 9010, New Zealand.

\section{Authors' contributions}

JG carried out the analyses and compiled earlier drafts under supervision by AIR and RM. AIR had input into survey design, in collaboration with HSC staff; contributed to study conception and design; provided input into prior drafts and was responsible for the final submitted draft. RM contributed to the conception and all drafts. HD was responsible for an initial concept paper and contributed to each draft. All authors read and approved the final manuscript.

\section{Authors' information}

JG (MPH) is employed at the CDC in the People's Republic of China. AIR (PhD) is Director of the Cancer Society Social and Behavioural Research Unit. RMCG (PhD) is Professor of Health Promotion in the Department of Preventive \& Social Medicine which hosts the SBRU. HD (PhD) is now CEO of Oritain Global Ltd. and a Director of Forensic Solutions NZ Ltd.

\section{Competing interests}

Dr Reeder serves on the National Health Promotion Advisory Committee of the Cancer Society of New Zealand Inc. Prof McGee serves on the Board of the Otago-Southland Division of the Cancer Society of New Zealand Inc.

Received: 11 January 2011 Accepted: 6 June 2011

Published: 6 June 2011

\section{References}

1. Silbereisen RK, Eyferth K: Development as action in context: problem behavior and normal youth development Berlin: Springer-Verlag; 1986.

2. Taras H: Physical activity and student performance at school. J School Health 2005, 75(6):214-8.

3. Eccles JS, Barber BL, Stone M, Hunt J: Extracurricular activities and adolescent development. J Social Issues 2003, 59(4):865-889.

4. Elder C, Leaver-Dunn D, Wang MQ, Nagy S, Green L: Organized group activity as a protective factor against adolescent substance use. Am J Health Behav 2000, 24(2):108-113.

5. Rainey CJ, McKeown RE, Sargent RG, Valois RF: Patterns of tobacco and alcohol use among sedentary, exercising, nonathletic and athletic yout. J School Health 1996, 66:27-32.

6. Mahoney $\mathrm{J}$, Stattin H: Leisure activities and adolescent antisocial behavior: the role of structure and social context. J Adolesc 2000, 23(2):113-27.

7. Page RM, Hammermeister J, Scanlan A, Gilbert L: Is school sports participation a protective factor against adolescent health risk behaviors? J Health Educ 1998, 29(3):186-192. 
8. Rodriguez D, Audrain-McGovern J: Team sport participation and smoking: Analysis with general growth mixture modeling. J Pediatr Psychol 2004, 29(4):299-308.

9. Eccles JS, Barber BL: Student council, volunteering, basketball, or marching band: What kind of extracurricular involvement matters? J Adolesc Res 1999, 14(1):10-43.

10. Begg D, Langley J, Moffitt T, Marshall S: Sport and delinquency: an examination of the deterrence hypothesis in a longitudinal study. Brit $J$ Sports Med 1996, 30(4):335-341.

11. Metzger A, Dawes N, Mermelstein R, Wakschlag L: Longitudinal modelling of adolescents' activity involvement, problem peer associations, and youth smoking. J Appl Develop Psychol 2011, 32:1-9.

12. Nowlin PR, Colder CR: The role of ethnicity and neighbourhood poverty on the relationship between parenting and adolescent cigarette use. Nicotine Tobacco Res 2007, 9(5):545-56.

13. Fredricks JA, Eccles JS: Is extracurricular participation associated with beneficial outcomes? Concurrent and longitudinal relations. Develop Psychol 2006, 42(4):698-713

14. Bohnert KM, Rios-Bedoya CF, Breslau N: Parental monitoring at age 11 and smoking initiation up to age 17 among Blacks and Whites. Nicotine \& Tobacco Res 2009, 11(12):1474-8.

15. Mulhall PF, Stone D, Stone B: Home alone: is it a risk factor for middle school youth and drug use? J Drug Educ 1996, 26:39-48.

16. Darling H, Reeder Al, Williams S, McGee R: Is there are a relation between school smoking policies and youth cigarette smoking knowledge and behaviours? Health Educ Res 2006, 21(1):108-115.

17. McDuff I: 2006 HSC Year 10 In-depth Survey. Report of Top-line Results. Wellington: Health Sponsoship Council; 2007.

18. Watson PD, Denny SJ, Adair V, Ameratunga SN, Clark TC, Crengle SM, Dixon RS, Fa'asisila M, Merry SN, Robinson EM, Sporle AA: Adolescents' perceptions of a health survey using multimedia computer-assisted selfadministered interview. ANZ J Publ Health 2001, 25(6):520-4.

19. Centers for Disease Control and Prevention. [http://www.cdc.gov/ tobacco/tobacco_control_programs/campaigns_events/got_a_minute/ parenting/].

20. Stata Corporation: Stata statistical software: release 9.0 Texas: Stata Corporation; 2005.

21. Altman DG: Practical statistics for medical research London: Chapman and Hall; 1999 .

22. Larson RW: Toward a psychology of positive youth development. Am Psychol 2000, 55(1):170-83.

23. Lisa MP, Frank JC: Parents, public policy, and youth smoking. J Policy Anal Management 2005, 24(1):93-112.

24. Castrucci BC, Gerlach KK, Kaufman NJ, Orleans CT: Tobacco use and cessation behavior among adolescents participating in organized sports. Am J Health Behav 2004, 28(1):63-71.

25. Melnick MJ, Miller KE, Sabo DF, Farrell MP, Barnes GM: Tobacco use among high school athletes and nonathletes: results of the 1997 youth risk behaviour survey. Adolesc 2001, 36(144):727-747.

26. Pate RR, Trost SG, Levin S, Dowda M: Sports participation and health related behaviors among U.S. youth. Arch Pediatr Adolesc Med 2000, 154(9):904-911.

27. West P, Sweeting H: "Lost souls" and "rebels": a challenge to the assumption that low self-esteem and unhealthy lifestyles are related. Health Educ 1997, 5:161-167.

28. Kaufman NJ, Feiden KL: Meeting overview and summary. Nicotine Tob Res 1999, 1(Suppl 1):S5-13.

29. Greene K, Banerjee SC: Examining unsupervised time with peers and the role of association with delinquent peers on adolescent smoking. Nicotine \& Tob Res 2009, 11(4):371-380.

30. Dollman J, Norton K, Norton L: Evidence for secular trends in children's physical activity behaviour. Brit J Sports Med 2005, 39(12):892-7.

31. Tobacco Advisory Group of the Royal College of Physicians: Nicotine addiction in Britain. London: Royal College of Physicians of London; 2000

doi:10.1186/1747-597X-6-12

Cite this article as: Guo et al:: Adolescents' leisure activities, parental monitoring and cigarette smoking - a cross-sectional study. Substance Abuse Treatment, Prevention, and Policy 2011 6:12.

\section{Submit your next manuscript to BioMed Central and take full advantage of:}

- Convenient online submission

- Thorough peer review

- No space constraints or color figure charges

- Immediate publication on acceptance

- Inclusion in PubMed, CAS, Scopus and Google Scholar

- Research which is freely available for redistribution

Submit your manuscript at www.biomedcentral.com/submit 